\title{
Reducing Stigma through Household-Based HIVIAIDS Education in Ghana: A Case for Behavioural and Attitudinal Change
}

\author{
Albert K. Koomson \\ Centre for Continuing Education \\ University of Cape Coast, Cape Coast, Ghana \\ albertkmsncce@yahoo.co.uk,mobile: 0243887343 \\ Paul D. Ahiatrogah \\ Centre for Continuing Education \\ University of Cape Coast, Cape Coast, Ghana \\ pauldela57@yahoo.com,mobile : 0200199074

\section{Brandford Bervell} \\ Centre for Continuing Education \\ University of Cape Coast, Cape Coast, Ghana \\ b_brandford@yahoo.co.uk, mobile : 0200937934
}

Doi:10.5901/mjss.2014.v5n4p311

Abstract

The study was aimed at reducing stigma through household - based HIV/AIDS education. It also targeted promoting behavioural and attitudinal change towards PLWHA in Ghana. A pretest - posttest design based on an intervention model was employed for the study. Quota sampling technique was used to select 3231 fathers and 3579 mothers while stratified sampling technique was used to select 3810 adolescent boys and 3552 girls from 3543 households for the study. The instrument used to collect data was a written questionnaire. The data was analysed using SPSS version 15. The study revealed that as a result of the intervention, more households in Ghana have now heard of HIVIAIDS. More people also now know that HIV is not the same as AIDS. They also realized that abstinence from sex and condom use are sure ways of avoiding contracting the virus. The study established that the major sources of information about HIVIAIDS are radio, TV, schools and print media. The attitude of respondents changed towards PLWHA drastically after the intervention. However, statistically significant differences were noted among fathers, mothers, adolescent boys and girls in the areas of having heard of HIVIAIDS before, awareness that HIV is not the same as AIDS, and what causes HIV AIDS. It is concluded that household - based education is a powerful mode of reducing stigma. It should therefore be pursued vigorously if the fight against HIVIAIDS is to succeed.

Keywords: Stigma, household-based education, behavioural and attitudinal change

\section{Introduction}

For many years now, the HIV epidemic has been a threat to mankind around the world. It has been increasing at an alarming rate since the first cases were reported in Ghana in the early 1980s. According to UNAIDS Report on the Global AIDS Crisis (2006), Ghana's population is estimated at 22,113,000 with an annual growth rate of $2.18 \%$ The life expectancy at birth is fifty-eight years for women and fifty six-years for men, but increasing rates of HIVIAIDS transmission is threatening to reduce life expectancy drastically. AIDS is affecting women and girls in increasing numbers such that globally, almost $50 \%$ of all people living with HIV are female and $76 \%$ of young people (aged $15-24$ years) living with HIV in sub-Saharan Africa are female. (UNAIDS/WHO, 2004).

The Ghana AIDS Commission continues to assert that stigmatization of the disease is one of the main obstacles to creating behavioural change. Stigmatization related to HIVIAIDS is frequently spread through lack of knowledge, traditional cultural practices and traditional beliefs. Many people deny that they have HIVIAIDS because of the stigma associated with the disease. Sex and sexually transmitted diseases are rarely discussed in public or in the family hence many Ghanaians learn about sex from peers. In the absence of effective cure, the only logical solution is prevention, 
which requires the dissemination of reliable information to the individual households. It is believed that increase awareness of the disease will help diminish the stigma associated with it. In this regards, creating awareness and changing perception and attitudes of the Ghanaian household through education becomes a necessary strategy to control the devastating effect of HIVIAIDS in Ghana.

\subsection{Theoretical Framework}

The theoretical basis for the study lies in the Theory of Planned Behavior (TPB) and Attitude Functions. TPB, which was developed by Azjen in 1985, is a modification of Azjen and Fishbein's 1975 Theory of Reasoned Action (TRA). The TRA assumes that a person's behavior is a function of his/her attitudes toward the behavior as well as subjective norms. The TPB extends this idea and takes into account performance of behaviors which are not entirely under the individual's control, by including the concept of perceived behavioral control. In the specific case of HIVIAIDS therefore, TPB argues that an individual's behavioral intent is a function of that individual's attitude, which reflects his/her evaluation of the HIVIAIDS associated behavior (UNAIDS, 2009)

Earlier researchers who examined the link between attitudes and behavior departed from the assumption that attitudes had a "directive or dynamic influence on individual response to all objects and situations" (Allport, 1935). According to Fazio (1989) the question of whether there really was a link between attitudes and behavior was initially considered only by few researchers.

\section{Literature Review}

Generally, knowledge about HIV infection is recognized as a critical component for the control and management of this disease (Valdiserri, Janssen, Buehler, Fleming, 2000). Several authors have attributed fear of contagion to inadequate HIV and AIDS related knowledge, whereas others have demonstrated a reduction in fears through improved AIDS education (Shaikh, Khan, Ross, Grimes, 2007, Mulligan, Seirawan, Galligan, Lemme, 2006).

The Ghana National Association of Teachers (GNAT) and the Teachers and Educational Workers Union (TEWU) of the Ghana Trades Union Congress undertook an assessment of the awareness of HIV and AIDS in the education sector and the needs of teachers and education workers in 2007. Six hundred and eighty one (681) respondents (86\% teachers and $14 \%$ education workers) were surveyed. The study revealed among the respondents: a high degree of awareness of HIV and AIDS (89\%) and of direct benefits of HIV and AIDS education (77.6\%); moderate attendance rate to HIV and AIDS education organized by Ghana Education Service $(58.2 \%)$; low readiness to know their HIV status (9.4\%); not very popular of condom use (15\% said they used condom during casual sex); and one fifth reported abstinence completely as a way of prevention of HIV infection (Baah et al, 2007). Too often, HIV education is not included in national education sector plans and policy frameworks. Some donor-driven programmes are seemingly too ambitious or poorly designed for the educational context. (Clarke, 2009)

Review of the literature of the causes and the pathogenesis of AIDS worldwide revealed that HIV is transmitted primarily by sex (anal, vaginal or oral sex with an infected partner), by injections (sharing contaminated needles for drug use or accidental piercing with a contaminated needle), or from infected mother to child through pregnancy or breastfeeding (Feinstein and Prentice, 2001) Although traces of HIV have been detected in body fluids (saliva, urine, faeces and tears) there is no evidence that HIV spreads through these fluids. Nor is it water-borne, air-borne or transmitted through mosquitoes and other insects (Cote, et al, 2004). In addition, homosexual men are usually heavy users of illicit drugs, alcohol, and rectal glucocorticoids (Fauci et al., 1998; Al-Bayati, 1999). In a study Al-Bayati, (2001) found that AIDS in Africa is caused by malnutrition, release of endogenous cortisol, and by opportunistic diseases. The study noted further that atrophy in the lymphoid tissue has been observed in HIV-negative people suffering from malnutrition.

HIV-affected households face increased expenditures, especially for health. (Alkenbrack et al, 2004). In Cambodia health spending was a significantly higher (22\%) percentage of household expenditures in $500 \mathrm{HIV}$-affected households than in the 500 unaffected households in the study (8\%). In communities highly affected by HIV, many children live in households in which their own parents have fostered or are fostering orphans. Researchers posited that all children in the household suffer the same contact information, economic and other deprivations resulting from spreading resources more thinly as a 'coping' response to the epidemic (Barnett and Whiteside, 2007). Parikh et al (2007) also found no statistically significant differences in most education, health and labour outcomes between orphans and the non-orphans with whom they live (cohort of 197 recent orphans and 528 non-orphans aged 9-16 years) in KwaZulu Natal, South Africa. 
The literature devoted to stigma and access to care falls roughly into three categories. These are: individuals, health care providers, and providers of ancillary and support services. According to Brimlow, Cook, and Seaton (2003), HIV-related stigma refers to all unfavorable attitudes, beliefs, and policies directed toward people perceived to have HIVIAIDS as well as toward their significant others and loved ones, close associates, social groups, and communities. Patterns of prejudice, which include devaluing, discounting, discrediting, and discriminating against these groups of people, play into and strengthen existing social inequalities - especially those of gender, sexuality, and race - that are at the root of HIV-related stigma.

HIVIAIDS-related stigma affects self-esteem, mental health, access to care, providers' willingness to treat people with HIV, violence, and HIV incidence. Interventions to reduce stigma are therefore crucial for improving care, quality of life, and emotional health for people living with HIV and AIDS. HIVIAIDS-related stigma has been specifically identified as a domestic policy challenge that must be addressed to reduce the number of new HIV infections, and eliminating stigma is a crucial element of global efforts (Institute of Medicine, 2001; Joint United Nations Programme on HIVIAIDS [UNAIDS], 2001; Henry J. Kaiser Family Foundation, 2002; Klein et al., 2002).

The literature on interventions and HIV-related stigma can be divided into three categories: statutory and regulatory, policy development, and programs and services. Most of the literature deals with the legal area. Considerably less attention has been devoted to programmatic interventions, which attempt to change attitudes and behavior. However, a multifaceted approach that goes beyond legal protections is necessary to address the social climate that sometimes appears to legitimize discrimination (Klein et al., 2002).

Studies reviewed show that stigma can be reduced through a variety of intervention strategies, including: Information, Counseling, Coping skills acquisition, and Contact. Even though stigma-reduction interventions work, most of the interventions were tested on small numbers of subjects. In addition, few studies looked at whether changes in attitudes and behaviors were sustained over time (Brown et al., 2001). Interventions to prevent HIV-related stigma and discrimination are integral components of the comprehensive approach to HIVIAIDS described by the New York State Department of Health AIDS Institute (Klein et al., 2002).

\subsection{Purpose of the Study}

The main objective of the research project is to make a case for the effectiveness of an interventional model for behavioural change through HIVIAIDS education in Ghana. The project also used educational interventional model to provide factual information about HIVIAIDS to the households. It also aims at transforming the social contexts; alter beliefs and superstitions about HIVIAIDS. The study used CCE, UCC teacher trainees pursuing Distance Education Programme in Education, to educate Ghanaian households on HIVIAIDS.

\section{Methodology}

\subsection{Research Design}

A pretest - post test design (Brogan \& Kutner, 1980)) was employed for the study. This design enabled the researchers to establish relationships between baseline and post intervention levels of knowledge. The study involved the baseline assessment of the levels of household's knowledge on HIV and AIDS in terms of its awareness, source of information, causes of the disease, modes of transmission, and post treatment evaluation of factual information about HIV and AIDS.This design was used for the study because it allowed relatively straightforward assessment of an intervention by detecting differences in learning outcomes between two points in time - before and after it. Furthermore, its implementation is relatively non-intrusive and its analysis is more straight forward.

The researchers were certain that the comparison gaps were not inadvertently exposed to the intervention and participants in the study did not communicate with one another about their experiences. The researchers also ensured that the groups did not differ in ways that could not be controlled.

\subsection{Participants}

The participants comprised of father, mother, an adolescent boy and girl in each household selected for the study. Three thousand five hundred and forty-three (3543) households in all the ten regions formed part of this study. 


\subsection{Instruments}

The main instrument used for this study was a written questionnaire. The questions were close-ended with pre categorized answers. The close-ended questions helped the research assistants to record answers quickly to promote easy analysis of the data.

\subsection{Sample and Sampling Procedure}

Quota sampling technique was used in the selection of father and mother in each household. On the other hand, stratified sampling was used to select the adolescent boy and girl between 14-19 years from each household. The quota sampling was used because it ensured that the number of sample units from different categories with specific characteristics such as father and mother appear in the sample. On the contrary, a stratified sampling technique was used for the adolescent boy and girl sample because random or systematic samples of a predetermined age group were obtained from each group. The total sample size for this study, therefore, was fourteen thousand one hundred and seventy two (14172) respondents.

Even though participants were not to declare their HIVIAIDS status, considering the sensitive nature of the topic, the researchers made sure that no ethical standards were compromised. Participants were assured of confidentiality in all the information they provided to the research assistants.

\subsection{Data Collection Process}

The research assistants were issued with introductory letters to the chiefs and assembly members of the community after going through training. They organized preliminary meetings with the selected households and introduced themselves to the household. The purpose of the project was also made known to the respondents. The Ghana Education Service and District Assemblies were also informed about the study.

Research assistants conducted interviews with their respondents. Each research assistant covered two households. The four respondents in each household were interviewed separately on one to one basis.

The interviews were conducted in the afternoons between $5.00 \mathrm{pm}-6.00 \mathrm{pm}$. This was to allow the research assistants and the children to return from school. It also allowed parents to return from their places of work. Each family or household was visited three times and each interview session did not last for more than 15 minutes. The first visit was the pre - treatment phase to find out the level of awareness of the disease. The second visit was the treatment phase. The research assistants used pictures, illustrations, and diagrams in passing on information on the disease. The post treatment phase was to find out what has changed. Each visit took 2 days. There was two weeks interval between each visit. The period was planned not to coincide with the farming season.

A field work manual was prepared for the research team. The manual spelt out guidelines on sampling procedures. The purpose and procedures of the study was also part of the manual used to introduce each interview session. Instruction sheets giving details on how to ask certain questions and how to record the answers were also provided.

At the end of each visit, the data gathered was checked to ensure that they were complete and accurate. Each questionnaire was numbered at the time of the interview. The instruments were labeled using the following indicators: $F$ Father, M - Mother, AB - Adolescent Boy, and AG - Adolescent Girl. This was checked by the supervisors before storing the questionnaire in envelopes marked for the purpose.

\subsection{Data Analysis}

The quantitative data was analyzed with SPSS version 15. Inferential statistics was used to analyze and discuss the data collected for the study. The independent sample t-test was used to determine whether statistically significant changes occurred as a result of the educational intervention introduced in the households. One way analysis of variance (ANOVA) and Tukey HSD Post-Hoc was executed to determine whether statistically significant differences occurred among the groups and the direction of the differences respectively. 


\section{Results}

The following hypotheses were formulated to guide the study. The hypotheses were tested at 0.05 level of significance.

\subsection{Hypothesis 1:}

There is no statistically significant change in the level of awareness of HIVIAIDS in Ghanaian Households before and after the intervention.

Table 1: T-test results of mean score on knowledge of HIVIAIDS before and after intervention

\begin{tabular}{|c|c|c|c|c|c|}
\hline & \multirow[b]{2}{*}{ No. of Subjects } & \multicolumn{2}{|c|}{ Mean Score } & \multirow[b]{2}{*}{$\mathrm{t}$-value } & \multirow[b]{2}{*}{ P-value } \\
\hline & & $\begin{array}{c}\text { Pre } \\
\text { Intervention }\end{array}$ & $\begin{array}{c}\text { Post } \\
\text { Intervention }\end{array}$ & & \\
\hline Hearing of HIVIAIDS & 14172 & 1.0544 & 1.0248 & 20.804 & $0.000^{*}$ \\
\hline HIV same as AIDS & 14172 & 1.5392 & 1.8679 & -83.308 & $0.000^{*}$ \\
\hline Difference between HIV and AIDS & 14172 & 2.9745 & 2.2320 & 125.489 & $0.000^{*}$ \\
\hline Avoid contracting the virus & 14172 & 2.5188 & 2.4980 & 5.848 & $0.000^{*}$ \\
\hline
\end{tabular}

The data analyzed in Table 1 shows the before and after intervention mean score for the four dimensions used in assessing level of awareness of HIVIAIDS. The results showed statistically significant increase in knowledge about hearing of HIVIAIDS ( $t=20.804$; $p<0.000)$; HIV being the same as AIDS ( $t=-83.308, p<0.000)$; difference between HIV and AIDS ( $t=125.489, P<0.000) ;$ and avoiding contracting the virus $(t=5.848, p<0.000)$ respectively. These findings suggest an improvement in the level of awareness about HIVIAIDS. Therefore, on the strength of the analysis reported in Table 1, the null hypothesis that there is no statistically significant change in the level of awareness of HIVIAIDS in Ghanaian Households before and after intervention was rejected.

\subsection{Hypothesis 2:}

There is no statistically significant change in the sources of information about HIVIAIDS in Ghanaian households before and after the intervention.

Table 2: T-test results of mean score on Source of Information

\begin{tabular}{lccccc}
\hline \multirow{2}{*}{ No. of Subjects } & \multicolumn{2}{c}{ Mean Score } & \multirow{2}{*}{\begin{tabular}{c} 
Pre \\
\cline { 3 - 4 }
\end{tabular}} & $\begin{array}{c}\text { Post } \\
\text { Intervention }\end{array}$ & Intervention \\
& & 3.3326 & 3.0775 & 54.111 & $0.000^{*}$ \\
\hline Source of Information & 14172 & &
\end{tabular}

Table 2 shows the mean scores of subjects' source of information before and after the intervention as 3.3326 and 3.0775 respectively ( $t=54.111, P<0.000)$. Hence, the research hypothesis that there is a statistically significant change in the sources of information about HIVIAIDS in Ghanaian households before and after the intervention is accepted.

\subsection{Hypothesis 3:}

There is no statistically significant change in what Ghanaian households perceive as the causes of HIVIAIDS before and after the intervention.

Table 3: T-test results of mean score on Causes of HIVIAIDS

\begin{tabular}{lccccc}
\hline & \multirow{2}{*}{ No. of Subjects } & \multicolumn{2}{c}{ Mean Score } & \multirow{2}{*}{ t-value } & P- value \\
\cline { 3 - 5 } & & $\begin{array}{c}\text { Pre } \\
\text { Intervention }\end{array}$ & $\begin{array}{c}\text { Post } \\
\text { Intervention }\end{array}$ & & \\
\hline Causes of HIVIAIDS & 14172 & 1.2705 & 2.3082 & -88.762 & $0.000^{\star}$ \\
\hline & & & & & \\
& & & & & \\
& & & & & \\
& & 315 & & &
\end{tabular}


In Table 3, the mean scores on what Ghanaian households perceive as the causes of HIVIAIDS before and after the intervention are 1.2705 and 2.3082 respectively, $(t=88.762, P<0.000$. It is therefore deduced from this result that the intervention has had a significant impact in Ghanaian households. Thus, the null hypothesis that there is no statistically significant change in what Ghanaian households perceive as the causes of HIVIAIDS before and after the intervention was not accepted.

\subsection{Hypothesis 4:}

There is no statistically significant change in what Ghanaian households consider as modes of transmitting HIVIAIDS before and after the intervention.

Table 4: T-test results of mean score on Mode of Transmission

\begin{tabular}{|c|c|c|c|c|c|}
\hline & \multirow[b]{2}{*}{ No. of Subjects } & \multicolumn{2}{|c|}{ Mean Score } & \multirow[b]{2}{*}{ t-value } & \multirow[b]{2}{*}{ P-value } \\
\hline & & $\begin{array}{c}\text { Pre } \\
\text { Intervention }\end{array}$ & $\begin{array}{c}\text { Post } \\
\text { Intervention }\end{array}$ & & \\
\hline Unprotected sex & 14172 & 1.1600 & 1.1433 & 15.525 & $0.000^{\star}$ \\
\hline Blood transfusion & 14172 & 1.5658 & 1.5277 & 23.693 & $0.000^{*}$ \\
\hline Mother to child & 14172 & 1.7365 & 1.6253 & 42.108 & $0.000^{*}$ \\
\hline Deep kissing & 14172 & 1.8643 & 1.8649 & -3.001 & $0.000^{*}$ \\
\hline Use of contaminated sharp objects & 14172 & 1.6602 & 1.5631 & 39.052 & $0.000^{\star}$ \\
\hline Others & 14172 & 1.8165 & 1.7671 & 27.115 & $0.000^{*}$ \\
\hline
\end{tabular}

The data analysed in Table 4 gives the mean scores of what Ghanaian households consider as modes of transmitting HIVIAIDS before and after the intervention. The results showed significant change in knowledge about unprotected sex $(t=15.525, p<0.000)$; blood transfusion, $(t=23.693, p<0.000)$; mother to child $(t=42.108, p<0.000$. Similar results were recorded for deep kissing ( $t=-3.001, p<0.000)$; use of contaminated sharp objects $(t=39.052, p<0.000)$ and others $(\mathrm{t}=27.117, \mathrm{p}<0.000$. Thus, on the strength of the analysis reported in Table 4 , the hypothesis that there is no statistically significant difference in what Ghanaian households consider as modes of transmitting HIVIAIDS was rejected.

\subsection{Hypothesis 5:}

There is no statistically significant change in the attitude of Ghanaian households towards People Living With HIVIAIDS (PLWHA) before and after the intervention

Table 5: T-test results of mean score on Attitude towards PLWHA

\begin{tabular}{|c|c|c|c|c|c|}
\hline & \multirow[b]{2}{*}{ No. of Subjects } & \multicolumn{2}{|c|}{ Mean Score } & \multirow[b]{2}{*}{ t-value } & \multirow[b]{2}{*}{ P-value } \\
\hline & & $\begin{array}{c}\text { Pre } \\
\text { Intervention }\end{array}$ & $\begin{array}{c}\text { Post } \\
\text { Intervention }\end{array}$ & & \\
\hline Eat from the same bowl with PLWHA & 14172 & 1.4030 & 1.0715 & 83.828 & $0.000^{*}$ \\
\hline Sleep on the same bed with them & 14172 & 1.4236 & 1.0768 & 86.728 & $0.000^{*}$ \\
\hline Use the same sharp objects with them & 14172 & 1.9043 & 1.9435 & -24.033 & $0.000^{*}$ \\
\hline Share the same clothing with them & 14172 & 1.4401 & 1.1033 & 84.831 & $0.000^{*}$ \\
\hline Discriminate between PLWHA and Non-PLWHA & 14172 & 1.6939 & 1.9338 & -66.879 & $0.000^{*}$ \\
\hline
\end{tabular}

The data analysed in Table 5 shows the mean scores of the attitude of Ghanaian households towards People Living With HIVIAIDS (PLWHA). Pre and post intervention results revealed change in attitude in the areas of eating from the same bowl $(t=83.828, p<0.000)$; sleeping on the same bed $(t=86.728, p<0.000)$; using same sharp objects $(t=-24.033$, $p<0.000)$, sharing the same clothing $(t=84.831, p<0.000)$; and discriminate between PLWHA and Non-PLWHA ( $t=-$ $66.879 ; p<0.000)$.

Further analysis was conducted to establish the reasons for the change in attitude not to discriminate between PLWHA and Non-PLWHA. The result of the analysis in that direction is presented in Table 6 
Table 6: T-test results of mean score on Reasons for not discriminating between PLWHA and Non-PLWHA

\begin{tabular}{lccccc}
\hline & & \multicolumn{2}{c}{ Mean Score } & & \\
\cline { 3 - 4 } & No. of Subjects & $\begin{array}{c}\text { Pre } \\
\text { Intervention }\end{array}$ & $\begin{array}{c}\text { Post } \\
\text { Intervention }\end{array}$ & & \\
& & 1.4464 & 1.1873 & 70.397 & $0.000^{*}$ \\
Need love and compassion & 14172 & 1.8783 & 1.8865 & -10.861 & $0.000^{*}$ \\
Entitled to Basic Human Rights & 14172 & 1.8171 & 1.9708 & -50.728 & $0.000^{*}$ \\
Fear of Infection & 14172 & 1.8582 & 1.9553 & -39.052 & $0.000^{*}$ \\
Don't know & 14172 & & & & \\
\hline
\end{tabular}

The data analysed in Table 6 depicts the pre and post intervention mean scores of the reasons why Ghanaian Households do not discriminate between PLWHA and Non-PLWHA. The results of the analysis portrays significant changes in need for love and compassion $(t=70.397, p<0.000)$, entitled to basic human rights $(t=-10.861, p<0.000)$; fear of infection $(t=-50.728, p<0.000)$ and those who do not know $(t=-39.052, p<0.000)$.

From the analyses on Tables 5 and 6 , the null hypothesis that there is no statistically significant difference in the attitude of Ghanaian households towards People Living With HIVIAIDS (PLWHA) before and after the intervention was rejected.

\subsection{Hypothesis 6:}

There is no statistically significant change among Ghanaian fathers, mothers, adolescents or children's' knowledge on HIVIAIDS before and after the intervention.

The study took cognizance of the fact that even though people live in the same household they may have different levels of awareness as far as the HIVIAIDS epidemic is concerned. A oneway ANOVA was executed to compare the knowledge levels of fathers, mothers, adolescence and children. The result of this analysis is shown in Table 7.

Table 7: Households level of awareness of HIVIAIDS (Oneway Anova)

\begin{tabular}{|c|c|c|c|c|c|c|}
\hline & & Sum of Squares & $\mathrm{df}$ & Mean Square & $\mathrm{F}$ & Sig. \\
\hline & Between Group & 251 & 3 & .084 & & \\
\hline \multirow[t]{2}{*}{ Pre: Have you heard of HIV and AIDS? } & Within Group & 342.056 & 14168 & .024 & 3.462 & $.016^{*}$ \\
\hline & Total & 342.307 & 14171 & & & \\
\hline \multirow{3}{*}{ Pre: Is HIV the same as AIDS? } & Between Group & 38.526 & 3 & 12.842 & & \\
\hline & Within Group & 3484.740 & 14168 & .246 & 52.242 & $.000 *$ \\
\hline & Total & 3521.265 & 14171 & & & \\
\hline \multirow{3}{*}{ Pre: What causes HIV and AIDS? } & Between Group & 496.782 & 3 & 165.594 & & \\
\hline & Within Group & 9920.942 & 14168 & 2.112 & 78.411 & $.000^{*}$ \\
\hline & Total & 0417.724 & 14171 & & & \\
\hline
\end{tabular}

The data analyzed in Table 7 indicates that statistically significant differences exists among fathers, mothers, adolescents and children in the area of having heard of HIVIAIDS before $F(2,14168)=3.462, p<.016$. In the same vain, a statistically significant difference was noted among fathers, mothers, adolescents and children in the area of awareness that HIV is the same as AIDS F $(2,14168)=52.242, p<.000$. Furthermore, in the area of what causes HIV and AIDS, a statistically significant difference was recorded among fathers, mothers, adolescents and children, $F(2,14168)=78.411$, $p<.000$

A multiple comparison was therefore carried out to establish the reality in the various communities. The results of this comparison is shown in Table 8 
Table 8: Multiple Comparisons

Tukey HSD

\begin{tabular}{|c|c|c|c|c|c|}
\hline Dependent Variable & (I)Family & (J)Family & $\begin{array}{l}\text { Mean Difference } \\
(\mathrm{I}-\mathrm{J})\end{array}$ & Std. Error & Sig \\
\hline \multirow{12}{*}{ Pre: Have you heard of HIV and AIDS } & \multirow{3}{*}{ Father } & Mother & -.002 & .004 & .962 \\
\hline & & Adolescent Boy & .005 & .004 & .492 \\
\hline & & Adolescent Girl & -.006 & .004 & .346 \\
\hline & \multirow{3}{*}{ Mother } & Father & .002 & .004 & .962 \\
\hline & & Adolescent Boy & .007 & .004 & .204 \\
\hline & & Adolescent Girl & -.004 & .004 & .626 \\
\hline & \multirow{3}{*}{ Adolescent Boy } & Father & -.005 & .004 & .492 \\
\hline & & Mother & -.007 & .004 & .204 \\
\hline & & Adolescent Girl & $-.012^{*}$ & .004 & .008 \\
\hline & \multirow{3}{*}{ Adolescent Girl } & Father & .006 & .004 & .346 \\
\hline & & Mother & .004 & .004 & .626 \\
\hline & & Adolescent Boy & $.012^{*}$ & .004 & .008 \\
\hline \multirow{12}{*}{ Pre: Is HIV the same as AIDS? } & \multirow{3}{*}{ Father } & Mother & $.068^{*}$ & .012 & .000 \\
\hline & & Adolescent Boy & $-.051^{*}$ & .012 & .000 \\
\hline & & Adolescent Girl & $.073^{\star}$ & .012 & .000 \\
\hline & \multirow{3}{*}{ Mother } & Father & $-.068^{*}$ & .012 & .000 \\
\hline & & Adolescent Boy & $-.119^{\star}$ & .012 & .000 \\
\hline & & Adolescent Girl & .005 & .012 & .978 \\
\hline & \multirow{3}{*}{ Adolescent Boy } & Father & $.051^{*}$ & .012 & .000 \\
\hline & & Mother & $.119 *$ & .012 & .000 \\
\hline & & Adolescent Girl & $.124^{*}$ & .012 & .000 \\
\hline & \multirow{3}{*}{ Adolescent Girl } & Father & $-.182^{*}$ & .012 & .000 \\
\hline & & Mother & .076 & .012 & .978 \\
\hline & & Adolescent Boy & $-.406^{*}$ & .012 & .000 \\
\hline \multirow{12}{*}{ Pre: What causes HIV and AIDS? } & \multirow{3}{*}{ Father } & Mother & $.182^{\star}$ & .035 & .000 \\
\hline & & Adolescent Boy & -.076 & .035 & .124 \\
\hline & & Adolescent Girl & $-.406^{*}$ & .035 & .000 \\
\hline & \multirow{3}{*}{ Mother } & Father & $.182^{\star}$ & .035 & .000 \\
\hline & & Adolescent Boy & $.258^{*}$ & .034 & .000 \\
\hline & & Adolescent Girl & $-.224^{*}$ & .034 & .000 \\
\hline & \multirow{3}{*}{ Adolescent Boy } & Father & -.076 & .035 & .124 \\
\hline & & Mother & $-.258^{\star}$ & .034 & .000 \\
\hline & & Adolescent Girl & $-.482^{*}$ & .034 & .000 \\
\hline & \multirow{3}{*}{ Adolescent Girl } & Father & $.406^{*}$ & .035 & .000 \\
\hline & & Mother & .224 & .034 & .000 \\
\hline & & Adolescent Boy & $.482^{*}$ & .034 & .000 \\
\hline
\end{tabular}

${ }^{*}$ The mean difference is significant at the .05 level

The analysis in Table 8 shows that in the case of having heard of HIVIAIDS before, the direction of the difference in the level of awareness lies between adolescents boy and girl. In the case of father-mother; the mother-adolescent, and father-child the differences are just marginal. However, in the case of knowing that HIV is the same as AIDS the direction of differences exist on all the four fronts except between mothers and children. Similarly, the directions of significant differences were noted among all four groups except father and adolescent.

There is evidence which suggests that the levels of awareness of the HIVIAIDS epidemic among fathers, mothers, adolescents and children are not the same.

\section{Discussion}

The study reveals that as a result of the intervention, more households in Ghana have now heard of HIVIAIDS and that HIV is not the same as AIDS. The study further revealed that the major sources of information about HIVIAIDS are radio, TV and schools both before and after intervention. However, print media became prominent as one major source of 
information. Furthermore, abstinence from sex and condom use were identified as ways of avoiding contracting the virus. This finding collaborate earlier studies carried out on mass media exposure which revealed that there is a link between behavioural intent and behavior. MacIntyre et al. (2001), in their study of condom use among men in Uganda, Kenya and Zambia found that men in Kenya and Uganda who listened to the radio on a daily basis were significantly more likely to report behavior change than those who did not listen. However, this relationship was not significant for Zambia. Karlyn (2001) found a similar exposure in Mozambique, where adults who recalled the campaign messages were almost twice as likely (odds ration 1.9) to try to change their behavior as those who did not recall these same messages. Interestingly, this study included a measure of self-efficacy to measure intent to carry out the targeted behavior after exposure to a certain message.

The study further established that unprotected sex is the major mode of transmitting HIVIAIDS. There was also an increase in awareness of blood transfusion and mother to child as modes of transmitting the disease. This finding is consistent with Dinesh \& Gopalakrishnan (2003) study which identified sexual transmission, blood transfusion, and mother to child transmission as the major modes of transmission of the virus.

It also came out clearly that even though the levels of awareness of the HIVIAIDS epidemic among fathers, mothers, adolescents and children increased, they are not the same. It is heartening to note that the intervention has raised the knowledge level of the four categories of respondents. What is frightening is the fact that some strong beats and pieces of misconceptions that still exit in the communities about how to find a cure for the HIVIAIDS. Some still hold the view that sex with virgin female could cure STDs. This misconception calls for continuous education and strong media advocacy.

Another finding was that respondents' attitude changed towards PLWHA drastically after the intervention because they realized that PLWHA need love and compassion from people. This is not a new development. Brown et al (2001) used peer education and workshops, street interviews, conversations with PLWHAs, and concerts to improve attitude towards PLWHA by encouraging acceptance and compassion. The effect of each intervention was measured by the participants' willingness to sit next to, eat with, and visit PLWHAs. The results showed a significant increase in positive attitudes towards PLWHAs on all measures and a reduction in the number of participants who sought isolation for PLWHAs.

\section{Conclusion}

It is obvious that targeting households in the fight against stigmatization through education is a very powerful intervention measure because the attitude of Ghanaians changed towards PLWHA drastically. It is now clear that PLWHA need love and compassion from other people.

\section{References}

Al-Bayati, M.A. (1999). Get All The Facts: HIV does not Cause AIDS. Toxi-health International, Dixon, California. Retrieved $26^{\text {th }}$ Nov.2009 from: http://www.toxi-health.com

Al-Bayati, M.A. (2001). HIV does not cause aids: Contribution of Corticosteroids, Illicit Drugs, and Malnutrition to the Pathogenesis of AIDS. Retrieved 26th Nov.2009 from: http://www.virusmyth.com/aids/hiv/mabcortico.htm

Alkenbrack S, Chettra T, Forsythe S. (2004). The social and economic impact of HIVIAIDS on families with adolescents and children in Cambodia. Ministry of Social Affairs and the POLICY Project.

Allport, G. (1935). "Attitudes" in A Handbook of Social Psychology (pp. 798-844). Worchester, MA: Clark University Press

Azjen, I. (1985). From Intentions to Actions: A theory of Planned Behaviour. In J. Kuhl,, \& J. Beckman (Eds.), Action-control: From cognition to behaviour (pp. 11-39) Heidelberg: Springer.

Azjen, I. \& Fishbein, M. (1975). Beliefs attitude, intention and behaviour: An introduction to theory and research. Reading, MA: AddisonWesley.

Baah, A. Jarl, Y. L. \& Otoo, K. N. (2007). An assessment of the awareness of HIVIAIDS in the education sector and the needs of teachers and educational workers living with HIVIAIDS in Ghana: Survey results. Ghana National Association of Teachers, GNAT; Teachers and Educational Workers' Union (TEWU) of Ghana Trade Union Congress,. 37 p. http://data.eiie.org/Contents/contents.asp

Barnett T and Whiteside A (2007). Poverty and HIV: Impact, Coping and Mitigation Policy. In Cornia, Giovanni Andrea (ed.).AIDS, public policy and child well-being. 2d edition. Florence: UNICEF-Innocenti Research Centre. http://www.unicef-irc.org/cgibin/unicef/Lunga.sql?ProductID=476

Brimlow, D. L. Cook, J. S. \& Seaton, R. (2003). Stigma and HIVIAIDS: A Review of the Literature. U.S. Department of Health and Human Services. Rockville MD

Brogan, D.R. \& Kutner, M. H. (1980). Comparative analysis of pretest-posttest research designs. The American Statistician, 34(4), 229- 
232

Brown L, Trujillo L, MacIntyre K. (2001). Interventions to reduce HIV/AIDS stigma: What have we learned? Horizons Program, Tulane University.. p. 15. Available at: Retrieved July 2009 from:. www.popcouncil.org/horizons /horizons.html.

Clarke, D. ( 2009). Heroes and villains: Teachers in the education response to HIV. Paris: UNESCO, International Institute for Educational Planning.

Cote, A. Sobela, F. Dzokoto, A. \& Nzambi, K. (2004). Transactional sex is the driving force in dynamics of HIV in Accra, Ghana. AIDS, 18,19

Dinesh, P. and Gopalakrishnan, S. (2003) Impact of Training on Knowledge of Transmission and Prevention of Sexually Transmitted Infections Including HIVIAIDS of Functionaries of Non-Governmental Organisations. Indian Journal of Community Medicine Vol. XXVIII, No. 4.

Fauci A.S.; Braunwald, E.; Isslbacher, K.J.; (1998). Harrison's Principles of Internal Medicine. (McGraw-Hill Companies, Inc. New York USA, ed. 14

Fazio, R. H. (1989), "On the Power and Functionality of Attitudes: The Role of Attitude Accessibility." in Attitude Structure and Function, ed. Anthony R. Pratkanis, Steven J. Breckler, and Anthony G. Greenwald, Hillsdale, NJ: Erlbaum, 153-179.

Feinstein, N. \& Prentice, B. (2001) Gender and AIDS Almanac, UNAIDS, USA

Henry J. Kaiser Family Foundation (2002). Policy Brief: Critical Policy Challenges in the Third Decade of the HIVIAIDS Epidemic. Menlo Park, CA: The Henry J. Kaiser Family Foundation.

Institute of Medicine (2001). No Time to Lose: Getting More from HIV Prevention. Washington, DC: National Academy Press.

Joint United Nations Programme on HIVIAIDS (UNAIDS). (2001). HIV related human rights guidelines. In: Together We Can. Geneva, Switzerland: UNAIDS; p. 17.

Karlyn, A. S. (2001). The Impact of a Targeted Radio Campaign to Prevent STIS and HIVIAIDS in Mozambique. AIDS Education and Prevention, 13(5), 438-451

Klein SJ, Karchner WD, O'Connell DA. (2002). Interventions to prevent HIV-related stigma and discrimination: findings and recommendations for public health practice. J Public Health Manage Pract.;8(6):44-53.

Macintyre, K. Brown, L., \& Sosler, S. (2001). "Its not what you know but who you knew": Examining the relationship Between Behaviour Change and HIVIAIDS Mortality in Africa. AIDS Education and Prevention, 13(2), 160-174

Mulligan R, Seirawan H, Galligan J, Lemme S (2006). The effect of an HIVIAIDS educational program on the knowledge, attitudes, and behaviors of dental professionals. J Dent Educ, 70(8):857-68.

Parikh A, et al. 2007. Exploring the Cinderella myth: Intrahousehold differences in child wellbeing between orphans and non-orphans in Amajuba district, South Africa. AIDS 21; (Supl 7): S95-S103.

Shaikh FD, Khan SA, Ross MW, Grimes RM (2007). Knowledge and attitudes of Pakistani medical students towards HIV-positive and/or AIDS patients. Psychol Health Med, 12(1):7-17.

UNAIDS. (2009).What countries need: Investments needed for 2010 targets. Geneva, UNAIDS. http://data.unaids.org/pub /Report/2009/20090210 investments needed 2010 en.pdf

UNAIDS: Report on the global AIDS epidemic (2006). Retrieved 10, Sept. 2009 from: [http://data.unaids.org/pub /GlobalReport/2006/Annex2_Data_en.xls] Geneva.

UNAIDS/WHO, (2004). Policy Statement on HIV testing. Global reference Group on HIVIAIDS and Human Rights. Retrieved 11 March 2009 from: http://www.who.int/rpc/research_ethics/hivtestingpolicy_en_pdf.pdf

Valdiserri RO, Janssen RS, Buehler JW, Fleming PL (2000). The context of HIVIAIDS surveillance. J Acquir Immune Defic Syndr , (25):97-104. 